\title{
Značajke anestezioloških postupaka kod transplantacije bubrega
}

\section{Specificities of anesthesia management for kidney transplantation}

\author{
Lara Valenčić*, Ivana Koraca Chinchella, Kazimir Juričić
}

\begin{abstract}
Sažetak. Transplantacija bubrega predstavlja najbolju metodu liječenja terminalne faze kronične bubrežne bolesti. Pripremu pacijenata za zahvat vodi tim u koji su uključeni nefrolog, kirurg - urolog, anesteziolog te liječnik obiteljske medicine, čija je međusobna suradnja nezaobilazni dio skrbi o pacijentu. $U$ prijeoperacijskoj pripremi anesteziolog se susreće s brojnim komorbiditetima, kompleksnom anamnezom te širokim spektrom pacijentove medikamentozne terapije uz naglasak na kardiovaskularne bolesti koje predstavljaju najčešći uzrok smrtnosti u ovoj skupini pacijenata. Pojavnost hematoloških, metaboličkih, respiratornih i endokrinih bolesti česta je, te je iznimno važna optimalizacija pacijentova općeg stanja prije operacijskog zahvata. Transplantacija bubrega je zahvat koji se obično ne može planirati i prema njemu se treba ponašati kao prema hitnom zahvatu, čime se povećava rizik razvoja komplikacija. Za vrijeme samog zahvata koji se izvodi u općoj, balansiranoj anesteziji, uloga anesteziologa je poznavanje farmakokinetike i farmakodinamike lijekova te vođenje anestezije koja će omogućiti urednu funkciju perfuzije presatka, što se postiže održavanjem adekvatnih vrijednosti krvnog tlaka. Važno je pravovremeno započinjanje antibiotske i imunosupresivne terapije uz zadovoljavajuću analgeziju. U daljnjem poslijeoperacijskom tijeku nužno je rano prepoznavanje i prevencija mogućih komplikacija kako bi se spriječilo neželjeno odbacivanje bubrežnog presatka.
\end{abstract}

Ključne riječi: održavanje anestezije; prijeoperacijska priprema; poslijeoperacijska skrb; terminalna bubrežna bolest; transplantacija bubrega

\begin{abstract}
Kidney transplantation represents the best method for treating end-stage renal disease. The procedure is led by a team involving a nephrologist, a urologist, an anesthesiologist and a family medicine doctor whose cooperation is an indispensable part of patient care. The anesthesiologist encounters numerous patient's comorbidities with a complex medical history and a wide range of medications. The emphasis is set on cardiovascular diseases which are the most common cause of mortality in this group of patients. The incidence of hematological, metabolic, respiratory and endocrine diseases is common, and it is extremely important to optimize the patient's general condition prior to surgery. Kidney transplantation usually cannot be planned so it should be treated as an emergency, increasing the risk of complications. During the procedure that is performed under general, balanced anaesthesia, the role of the anesthesiologist is to know pharmacokinetics and pharmacodynamics of the drugs. Maintenance of blood pressure during anesthesia ensures an adequate kidney transplant perfusion. Early antibiotic and immunosuppressive therapy with satisfactory analgesia is important. In the postoperative course, early identification and prevention of possible complications is necessary to prevent unwanted kidney transplant rejection.
\end{abstract}

Key words: end-stage renal disease; kidney transplantation; maintenance of anesthesia; preoperative preparation; postoperative care
Klinika za anesteziologiju, intenzivnu medicinu i liječenje bola, Klinički bolnički centar Rijeka, Rijeka, Hrvatska

\author{
*Dopisni autor: \\ Lara Valenčić, dr. med. \\ Klinika za anesteziologiju, intenzivnu \\ medicinu i liječenje bola \\ Krešimirova 42, 51000 Rijeka \\ E-mail: lara.valencic@medri.uniri.hr
}

http://hrcak.srce.hr/medicina 


\section{UVOD}

Transplantacija bubrega predstavlja najbolju metodu liječenja terminalne faze kronične bubrežne bolesti. Pacijenti predviđeni kao kandidati za transplantaciju obično imaju niz komorbiditeta koje sa sobom prati bubrežna bolest u uznapredovaloj fazi. Upravo ta činjenica zahtijeva veliku predanost i stručnost od strane anesteziologa kako bi pacijent bio na najbolji mogući način pripremljen za sam zahvat $\mathrm{u}$ cilju prevencije ranih $\mathrm{i}$

U prijeoperacijskoj pripremi, anesteziolog se susreće $\mathrm{s}$ brojnim komorbiditetima te širokim spektrom pacijentove medikamentozne terapije. Bubrežna bolest reflektira se na većinu organskih sustava, što ukazuje na važnost dobre prijeoperacijske pripreme pacijenta. Osobiti naglasak stavlja se na kardijalni status pacijenta, budući da kardiovaskularne bolesti predstavljaju vodeći uzrok smrtnosti ove skupine pacijenata.

kasnih komplikacija. Pripremu pacijenata za zahvat vodi tim u koji su uključeni nefrolog, kirurg - urolog, anesteziolog te liječnik obiteljske medicine. Iznimno je važna njihova međusobna suradnja kako bi pacijent u trenu transplantacije bio optimalnog općeg stanja ${ }^{1,2}$.

\section{PRIJEOPERACIJSKA PRIPREMA}

U prijeoperacijskoj pripremi pacijenata anesteziolog se susreće s brojnim komorbiditetima, kompleksnom anamnezom te širokim spektrom pacijentove medikamentozne terapije. Važno je da anesteziolog bude detaljno upoznat sa samom anatomijom i fiziologijom bubrega, kao i s bubrežnom bolešću te mogućnostima njezine dijagnostičke obrade i terapije. Nadalje, bitnu ulogu igra farmakokinetika i farmakodinamika lijekova koji se metaboliziraju te izlučuju putem urinarnog sustava. Bubrežna bolest reflektira se na veliku većinu organskih sustava, noseći sa sobom potencijalno brojne komorbiditete koje anesteziolog mora znati prilagoditi vođenju anestezije tijekom transplantacije bubrega, kao i mogućem utjecaju na rani i kasni poslijeoperacijski tijek oporavka².

\section{Kardiovaskularni sustav}

Kardiovaskularne bolesti predstavljaju najčešći uzrok smrtnosti kod pacijenata s kroničnom bubrežnom bolešću neovisno o stadiju ${ }^{2}$. Gotovo $80 \%$ pacijenata boluje od arterijske hipertenzije dok se u 25 \% javlja ishemijska bolest srca. Ostale moguće srčane manifestacije su kronično srčano zatajivanje uz potencijalnu akutizaciju u slučaju progresije osnovne bolesti, valvularna bolest srca, plućna hipertenzija te pojava različitih oblika aritmija. Veliki kirurški zahvati, među koje se ubraja i transplantacija bubrega, izazivaju katabolizam organizma, prilikom čega se aktiviraju kompenzacijski mehanizmi koji uključuju tahikardiju, hipertenziju, volumnu retenciju i hiperkoagulabilnost kako bi se zadržala homeostaza kardiovaskularnog sustava. Ovaj odgovor organizma na kirurški stres može biti poremećen kod bubrežnih pacijenata u terminalnoj fazi bolesti. S obzirom na navedeno, važna je prijeoperacijska procjena kardijalnog statusa pacijenata.

Među zemljama postoje određena odstupanja u pristupu prijeoperacijskoj procjeni kardijalnog statusa pacijenata s terminalnom bubrežnom bolesti, no sljedeće smjernice temelj su procjene pacijenata u većini zemalja:

- Prema europskim smjernicama za transplantaciju bubrega (ERBP, engl. European Renal Best Practice), detaljna anamneza uz fizikalni pregled, radiogram grudnih organa s 12-kanalnim EKG zapisom, dovoljni su za inicijalnu evaluaciju pacijenata ako nema značajnih čimbenika rizika.

- Pacijentima bez ranije poznate šećerne bolesti ili kardiovaskularne bolesti s dva ili više prisutnih kliničkih čimbenika rizika koji uključuju uz životnu dob (žene starije od 55 godina, muškarci stariji od 45 godina), arterijsku hipertenziju, displipidemiju, pušenje, hipertrofiju lijevog ventrikla, obiteljsku anamnezu uranjenih koronarnih bolesti, perifernu vaskularnu bolest te dijalizu u trajanju od više od jedne godine, dodatno je indiciran ehokardiografski pregled srca ili neinvazivno stresno opterećenje miokarda (scintigrafijska perfuzija miokarda, dobutaminski test). Ako su testovi pozitivni, indicirana je daljnja invazivna kardiološka obrada (koronarografija).

- Pacijentima s ranije poznatom šećernom i kardiovaskularnom bolesti, ako ne postoji niti jedan 
ranije navedeni čimbenik rizika te šećerna bolest tip I koja traje < 15 godina i tip II < 10 godina, dovoljno je učiniti 12-kanalni EKG zapis, ehokardiografski pregled srca te farmakološki stres opterećenja srca.

- Pacijentima s ranije poznatom šećernom i kardiovaskularnom bolesti, ako postoji bilo koji čimbenik rizika te šećerna bolest tip I koja traje > 15 godina i tip II > 10 godina, indiciran je 12-kanalni EKG-zapis, ehokardiografski pregled srca te koronarografija.

- Ne preporučuje se neinvazivni test opterećenja na pokretnoj traci (ergometrija) radi autonomne disfunkcije zbog podliježeće šećerne bolesti uz visoku stopu hipertrofije lijevog ventrikla $u$ ovoj skupini pacijenata, te zbog slabe tolerancije napora uslijed osnovne bolesti. Prednost se daje farmakološkom stres opterećenju srca ${ }^{3}$.

\section{Hematološki sustav}

Anemija u terminalnoj fazi bubrežne bolesti može biti posljedica nekoliko uzroka kao što su smanjena sinteza eritropoetina, što posljedično dovodi do skraćenog životnog vijeka eritrocita, kao i supresija koštane srži različitim imunosupresivima iz kronične terapije ili visokim razinama ureje. Posljedično rezultira manjkom željeza, folne kiseline, vitamina B6 i B12 ${ }^{1}$. U standardnoj obradi pacijenata, uz nalaze krvne slike i biokemije, indicirana je kontrola vrijednosti željeza, feritina i saturacije transferina. Ako je saturacija transferina $<20 \%$ i vrijednost feritina $<100 \mathrm{ng} / \mathrm{mL}$, primjenjuju se intravenski preparati željeza. Liječenje željezom može korigirati anemiju čak i kod suboptimalnih endogenih razina eritropoetina te je ujedno i financijski manje zahtjevno rješenje. Ako se započinje s tretmanom eritropoetinom, terapiju treba započeti nekoliko tjedana prije same transplantacije ${ }^{4}$. Za sam zahvat transplantacije bubrega potrebno je rezervirati dvije doze filtriranih koncentrata eritrocita. Zbog cirkulirajućih uremijskih toksina moguća je smanjena funkcija trombocita, što dovodi do hemoragijske dijateze. Trombocitopenija je zabilježena u 16 do $55 \%$ pacijenata 5 .

\section{Endokrini sustav}

Prema dosadašnjim istraživanjima u $44 \%$ pacijenata uzrok terminalne faze bubrežne bolesti je dijabetička nefropatija. Kardiovaskularna obolje- nja, kao što je ranije spomenuto, uzrok su mortaliteta ove skupine pacijenata. Najčešće razvijene komplikacije su periferna vaskularna bolest u vidu dijabetičke angiopatije i polineuropatije, što nerijetko rezultira mutilacijskim zahvatima, poput amputacija na ekstremitetima, zatim infekcije te malnutricija koja je česta u ovih pacijenata. Važnu ulogu u adekvatnoj pripremi pacijenata za zahvat uključuje kontrola krvnog tlaka, razina glukoze u krvi (GUK), korekcija lipidnog i nutritivnog statusa pacijenata $^{6}$. Prema smjernicama Hrvatskog društva za anesteziologiju, reanimatologiju i intenzivnu medicinu (HDARIM), kontrola vrijednosti GUK-a trebala bi se vršiti neposredno prije samog zahvata te je, ako su vrijednosti GUK-a više od $10 \mathrm{mmol} / \mathrm{L}$, potrebna korekcija brzodjelujućim inzulinom ${ }^{7}$. Osim navedenog, među ostale endokrine poremećaje koji prate terminalnu fazu bubrežne bolesti također se ubrajaju disocijacija između sinteze aldosterona i funkcije renin-angiotenzinskog sustava, abnormalna volumska regulacija posljedično poremećaju funkcioniranja vazopresina, izmijenjeni odgovor organskih sustava na hormonski, najčešće stresni kortizolski podražaj. Sekundarni hiperparatireoidizma najčešći je uzrok razvoja osteoporoze ovih pacijenata, što treba imati na umu prilikom namještanja pacijenata na operacijskom stolu, kao i zbog mogućih promjena vratne kralježnice, što može predstavljati potencijalni problem prilikom retrofleksije vrata za postupak laringoskopije i orotrahealne intubacije ${ }^{8}$.

\section{Poremećaji elektrolita i acido-bazne ravnoteže}

Poremećaj elektrolita gotovo neizostavno prati terminalnu bubrežnu bolest. Hiperkalijemija, hipokalcijemija, hiperfosfatemija i hipermagnezijemija najčešći su poremećaji elektrolita. Hiperkalijemija je uzrokovana inzulinskim deficitom i rezistencijom, prilikom čega se nedovoljno kalija unosi u stanice. Navedeni poremećaj kalija asimptomatski je sve dok se ne manifestiraju kardijalne komplikacije. Najčešće promjene na EKG zapisu manifestiraju se kao visoki, šiljati T-valovi, prolongacija PR segmenta, proširenje QRS kompleksa uz aplanirane P-valove. Posljedica su sinus arest, sinus bradikardija, ventrikularna tahikardija i fibrilacija. Kako bi se spriječile navedene, po život opasne komplikacije, potrebna je korekcija vrijednosti kalija ako prelazi > 5,5 mmol/L. Ako su una- 
toč provedenim medikamentoznim mjerama korekcije vrijednosti kalija zadrže povišenim, indicirano je provesti dijalizu. Poremećaj kalija i magnezija komplementarno se prati te je indicirano kontrolirati i po potrebi korigirati vrijednosti magnezija ${ }^{9}$. Kronična metabolička acidoza uslijed gubitka biokarbonata putem gastrointestinalnog sustava najčešće ne povisuje perioperacijski rizik, no potrebno je nadoknaditi bikarbonate ako je $\mathrm{pH}<7,1$. Najčešći problem anesteziologa vezan uz metaboličku acidozu je promjena miljea u kojem određeni anesteziološki lijekovi mogu ostvariti svoj učinak ${ }^{2}$.

\section{Respiratorni sustav}

Kod pacijenata u terminalnoj fazi bubrežne bolesti moguća je kongestija pluća s razvojem plućnog edema. Razlog tome može biti kardijalne etiologije s obzirom na ranije spomenute popratne kardiovaskularne bolesti, kao i volumno opterećenje. Navedeno se može liječiti diureticima te primjenom dijalize prije samog zahvata. Isto tako, postoji i sklonost razvoju infekcija. Indicirana je obavezna antibiotska profilaksa prethodno zahvatu, kao i bolusna imunosupresivna terapija u premedikaciji ${ }^{1}$.

\section{PREMEDIKACIJA TIJEKOM PRIJEOPERACIJSKE} PRIPREME PACIJENATA

\section{Antikoagulantna i antiagregacijska terapija}

Osobe predviđene za transplantaciju bubrega mogu pratiti komorbiditeti koji zahtijevaju dugotrajnu antikoagulantnu terapiju (varfarin) ili antiagregacijsku terapiju (klopidogrel, acetilsalicilna kiselina). Transplantacija bubrega je zahvat koji se obično ne može planirati i prema njemu se treba ponašati kao prema hitnom zahvatu. $U$ tom slučaju, anesteziolog se susreće s problemom potencijalno izraženijeg krvarenja tijekom operacijskog zahvata, budući da reverzija antikoagulantne terapije nije uvijek moguća kao kod elektivnih zahvata. Za pacijente na varfarinu konverziju je moguće učiniti primjenom vitamina $\mathrm{K} u$ dozi od 1 $-2 \mathrm{mg} / \mathrm{kg}$ ili svježe smrznute plazme u dozi od 10 - $15 \mathrm{mg} / \mathrm{kg}$ uz ciljne INR vrijednosti < 1,5. Isto tako, moguća je i primjena koncentrata protrombinskog kompleksa, kao što je, primjerice, Octaplex ${ }^{\circledR}$ (Octapharma Limited, Manchester M2 1AB,
United Kingdom). Za antiagregacijsku terapiju ne postoji mogućnost konverzije te se može primijeniti trombocitna infuzija ako dođe do izraženijih krvarenja. Profilaktička primjena ne preporučuje $\mathrm{se}^{10}$. Daljnja profilaksa poslijeoperacijskog tromboembolijskog incidenta nastavlja se subkutanom primjenom niskomolekularnog heparina.

\section{Antibiotska profilaksa}

Unatoč tome što je transplantacija bubrega zahvat visokog uspjeha, kao posljedica mogu se razviti brojne komplikacije. Jedna od njih je infekcija rane kirurškog reza. Definira se kao infekcija koja zahvaća isključivo sloj kože i potkožnog tkiva, a razvija se unutar 30 dana. Zabilježena je u $11 \%$ svih pacijenata koji su primili bubreg, a predisponirajući čimbenici su imunosupresivna terapija, starija životna dob, indeks tjelesne mase viši od 27, šećerna bolest s perifernim komplikacijama, vrijeme hladne ishemije bubrega više od 30 sati $\mathrm{i}$ trajanje zahvata više od 200 minuta. Prema konsenzusu svih zemalja profilaktička doza antibiotika mora se primijeniti unutar 60 minuta od kirurškog reza, najidealnije u prvih 30 minuta. Prvi red izbora su cefalosporini treće generacije uz prednost ceftriaksonu. Ako postoji alergija na penicilinsku skupinu antibiotika, antibiotik odabira je vankomicin ili klindamicin u kombinaciji $s$ gentamicinom ili fluorkinolonima. Kao i kod svih dugotrajnih zahvata, dozu treba ponoviti svaka 4 sata zahvata ${ }^{2,11}$.

\section{Imunosupresivna terapija}

Imunosupresivna terapija provodi se u dvije faze - fazi indukcije i fazi održavanja. Prije početka samog zahvata započinje se s fazom indukcije kako bi se spriječilo rano odbacivanje presatka. Najčešće je to kombinacija intravenskog metilprednizolona kombiniranog s monoklonalnim protutijelima usmjerenim na CD25 molekulu kao što je basiliksimab. Druga faza služi kao terapija održavanja kroz 3 - 6 tjedana kako bi se inducirala tolerancija, dok je posljednja i najdugotrajnija treća faza koja je doživotna ${ }^{12}$.

\section{Gastroprotektivna i antiemetska terapija}

Parenteralno se primjenjuju inhibitor protonske pumpe pantoprazol u dozi od $40 \mathrm{mg}$ i metoklopramid u dozi od $10 \mathrm{mg}$. Budući da se pantopra- 
zol gotovo isključivo metabolizira u jetri, nije potrebna prilagodba doze kod bubrežnog oštećenja. Klirens metoklopramida smanjuje se za $70 \%$ u pacijenata s teškim oštećenjem bubrežne funkcije $^{1}$.

\section{Anksiolitici}

Najčešće se kao peroralna doza sat vremena prije zahvata primjenjuje 7,5 mg midazolama. Primjena midazolama je sigurna kod pacijenata s teškim bubrežnim oštećenjem te je poluvijek eliminacije sličan onima kod zdravih osoba ${ }^{1}$

\section{PRIPREMA PACIJENATA ZA UVOD}

\section{U ANESTEZIJU}

Prema važećim smjernicama rutinsko praćenje uključuje pulsnu oksimetriju, 3-kanalni EKG monitor, neinvazivno mjerenje krvnog tlaka i kapnografiju. Izbjegava se invazivno mjerenje krvnog tlaka radi mogućih komplikacija kod kasnijeg formiranja fistule. Manžeta tlakomjera i periferni intravenski pristup postavljaju se na suprotnu ruku od one na kojoj se nalazi fistula. Neizostavna je i urinska kateterizacija uz praćenje satne diureze. Ako postoji, centralni venski dijalizni kateter može poslužiti kao venski put za aplikaciju lijekova, no za sam uvod u anesteziju dovoljna je periferna vena šireg promjera. Ako za to postoji indikacija zbog ranije spomenutih kardiovaskularnih komorbiditeta, za praćenje srčane akcije može se koristiti transezofagealna ili transtorakalna ehokardiografija ${ }^{1,13}$.

\section{UVOD U ANESTEZIJU}

Transplantacija bubrega izvodi se najčešće u općoj, balansiranoj anesteziji koja predstavlja kombinaciju intravenskih i inhalacijskih anestetika. U nekim centrima zahvat se može izvesti i u neuroaksijalnoj anesteziji koja u ovom slučaju nosi sa sobom i veći broj komplikacija. Neizbježno je da anesteziološki lijekovi mijenjaju hemodinamske odnose, stoga treba oprezno birati i dozirati lijekove uz individualnu prilagodbu pacijentu.

\section{Opiodi}

Najčešće korišteni su sufentanil, fentanil i remifentanil. Njihov metabolizam i eliminacija ne mijenja se značajnije kod poremećaja bubrežne funkcije. Morfij sa svojim aktivnim metabolitom morfij-6-glukuronidom podliježe renalnoj ekskreciji, te se posljedično pojačano akumulira u organizmu, čime dovodi do neželjene depresije respiracijskog i centralnog živčanog sustava. Nije lijek izbora za analgeziju transplantiranih pacijenata ${ }^{1,13}$.

Cilj anesteziologa prilikom vođenja anestezije za transplantaciju bubrega je duboka, balansirana anestezija uz adekvatnu mišićnu relaksaciju i dobru analgeziju. Krajnji cilj je održavanje perfuzije presatka, što osigurava dobru funkciju presatka. Kako bi se osiguralo dovoljno krvi i kisika bubregu, nužno je održavati adekvatni krvni tlak optimalizacijom intravaskularnog volumena.

\section{Hipnotici}

Rutinski se koristi propofol. Etomidat kao indukcijski agent održava hemodinamsku stabilnost no njegova najpoznatija nuspojava je supresija nadbubrežne žlijezde. Budući da primatelj bubrega dobiva imunosupresivnu terapiju ova vrsta supresije je kratkotrajna i od malog značenja. Ketamin i tiopental se koriste ako za to postoji indikacija temeljem pacijentova općeg stanja i podležećih bolesti ${ }^{13}$.

\section{Mišićni relaksansi}

Najčešće se primjenjuju nedepolarizirajući mišićni relaksansi poput rokuronija i atrakurija čija bubrežna eliminacija iznosi $10 \%$ za rokuronij te 10 - $40 \%$ za atrakurij i cis-atrakurij. Mogu se sigurno primijeniti kao lijekovi izbora za mišićnu relaksaciju. Atrakurij se smatra najpogodnijim lijekom izbora za mišićnu relaksaciju, budući da podliježe Hoffmanovoj eliminaciji u plazmi koja je neovisna o bubrežnoj funkciji. Njegova dostupnost ovisi o centru u kojem se provodi transplantacija. Sukcinilkolin može poslužiti kao lijek izbora kod intubacije u brzom slijedu ako za to postoji indikacija. Iznimno je važno naglasiti da je to lijek koji svojim djelovanjem u organizmu podiže razine kalija. Kako je ranije spomenuto, hiperkalijemija je jedna od najčešćih komplikacija bubrežne bolesti te se sukcinilkolin ne smije primijeniti ako su razine kalija u plazmi više od $5 \mathrm{mmol} / \mathrm{L}^{13,14}$. 


\section{Inhalacijski anestetici}

Sevofluran kao najčešće korišteni inhalacijski anestetik podliježe biodegradaciji u floridne ione i komponentu A koji su dokazano nefrotoksični. Ako uz sevofluran, protok svježih plinova iznosi minimalno $1 \mathrm{~L} / \mathrm{min}$ za izlaganje plinovima do 1 sat te minimalno $2 \mathrm{~L} / \mathrm{min}$ za izlaganje više od 1 sat, može se sigurno koristiti za anesteziju tijekom transplantacije bubrega. Osim toga, smanjuje perifernu vaskularnu rezistenciju, ima niži kardiodepresivni učinak i održava konstantan protok krvi kroz bubreg ${ }^{1,14}$.

\section{ODRŽAVANJE ANESTEZIJE}

Cilj anesteziologa prilikom vođenja anestezije tijekom transplantacije bubrega je duboka, balansirana anestezija uz adekvatnu mišićnu relaksaciju i dobru analgeziju. Krajnji cilj je održavanje dobre perfuzije presatka. Funkcija presatka direktno je povezana s perfuzijom presatka. Kako bi se osiguralo dovoljno krvi i kisika bubregu, nužno je održavati adekvatni krvni tlak, što se postiže optimalizacijom intravaskularnog volumena primjenom kristaloidnih tekućina, od čega su balansirane kristaloidne tekućine izbor. Uvriježeno je bilo mišljenje da primjena kristaloida koji u svom sastavu sadrže kalij kao što su Ringerov laktat ${ }^{\circledR}$ (B. Braun Adria d. o. o., Zagreb, Hrvatska), Plasma-Lyte ${ }^{\circledR}$ (Baxter d. o. o., Ljubljana, Slovenija) i Ionolyte $^{\circledR}$ (Fresenius Kabi, Zagreb, Hrvatska), mogu pogoršati hiperkalijemiju, no nedavna istraživanja dokazala su da su sigurne u primjeni kod bubrežnih pacijenata uz najbolji metabolički profil pacijenata koji su primali Plasma-Lyte ${ }^{\circledR 15,16}$. Preporučuje se učiniti kontrolu krvne slike i acido-baznog sustava prije te neposredno nakon reperfuzije. Kako bismo izbjegli hipoperfuziju presatka, cilj je izbjeći epizode hipotenzije koja je očekivana u trenutku reperfuzije bubrega. U svrhu postizanja zadovoljavajućih bubrežnih perfuzijskih tlakova, preporučuje se administracija 200 do $250 \mathrm{ml} 20 \%$ otopine manitola neposredno prije reperfuzije ${ }^{14}$. Budući da vazopresori svojim direktnim učinkom mogu dovesti do vazokonstrikcije renalnih krvnih žila, oprezno se mora balansirati krvni tlak i odvagnuti potencijalne štetnosti i koristi primjene određenih lijekova. Krvni preparati rijetko su potrebni tijekom zahva- ta ako je prijeoperacijski učinjena zadovoljavajuća korekcija anemije (Hgb > 70 g/L). Nadoknada krvnih derivata povećava rizik autoimune reakcije i mogućeg ranog odbijanja presatka. Neizostavna komponenta je i grijanja pacijenata aparatima $s$ grijanim zrakom ili grijačima tekućina ${ }^{13}$.

\section{Analgezija}

Epiduralna analgezija primjenjuje se ovisno o pacijentu i njegovim podležećim komorbiditetima. Kontraindikacije za navedeni postupak su heparinizacija koja je neizbježna prije dijalize, potencijalna koagulopatija ako su razine ureje visoke te hipotenzija koja može utjecati na vijabilnost presatka ${ }^{13}$. Ako se epiduralni kateter ne postavi, kupiranje bolova tijekom operacije postiže se primjenom visokopotentnih opioida, kao što su sufentanil ili fentanil u kombinaciji s paracetamolom. Kao što je ranije opisano, izbjegava se primjena morfija radi njegovih aktivnih metabolita ${ }^{14}$. Primjena nesteroidnih protuupalnih lijekova izbjegava se poradi potencijala za razvoja krvarenja, osobito u gastrointestinalnom sustavu te njihove nefrotoksičnosti kao opisanih nuspojava primjene ${ }^{17}$. U svrhu kupiranja bolova mnogi centri u kojima se provodi regionalna anestezija primjenjuju i periferni živčani blok pod nazivom blok transverzalnog trbušnog mišića (TAP, engl. transversus abdominis plane) blok. Navedenim postupkom pod kontrolom ultrazvuka dugodjelujući lokalni anestetik, najčešće levobupivakain, aplicira se u područje trbušne stijenke i obezboli navedeno područje. Ovakav oblik analgezije vremenski dulje kupira bol te smanjuje potrebu za korištenje opioida koji mogu dovesti do hipotenzije i potencijalno smanjene perfuzije bubrežnog presatka. Također, kirurg urolog može infiltrirati reznu ranu lokalno dugodjelujućim lokalnim anestetikom ${ }^{1,13,14}$.

\section{POSLIJEOPERACIJSKA SKRB}

U daljnjem tijeku potrebna je kontinuirana skrb radi razvoja kardiovaskularnih komplikacija koje zauzimaju vodeće mjesto te moguće ishemijsko-reperfuzijske ozljede presatka ${ }^{1}$. Navedeno se provodi $u$ jedinici intenzivne njega (JINJ) putem standardnog praćenja srčanog ritma, krvnog tlaka i pulsne oksimetrije. Potiče se rana ekstubacija kada su za to stvoreni uvjeti. Veoma je bitno pra- 
ćenje satne diureze te drenaža iz anatomskog mjesta kirurškog zahvata. Svakodnevno se kontrolira krvna slika, biokemija s bubrežnim i upalnim parametrima te acido-bazni status. Uputno je izbjegavati unošenje nefrotoksičnih lijekova. Daljnja volumna optimalizacija prilagođava se satnoj diurezi. Diskutabilno je koliko CVP služi kao objektivni hemodinamski parametar, budući da su u dosad provedenim studijama dobiveni različiti rezultati u ulozi CVP-a kao parametra kojim dobivamo uvid u intravaskularni status pacijenata i posljedično samu funkciju presatka. Veoma je važan nastavak imunosupresivne terapije. Ako postoje znakovi hipervolemije, elektrolitskog i acido-baznog disbalansa koji perzistiraju unatoč medikamentoznoj terapiji, indicirano je provesti dijalizno liječenje $\mathrm{e}^{12,14,18,19}$.

\section{ZAKLJUČAK}

Transplantacija bubrega predstavlja izazov u liječničkom poslu uz veoma bitan, multidisciplinaran pristup pacijentu. Uloga anesteziologa je neizostavna i zahtjevna, budući da o anesteziološkom menadžmentu tijekom zahvata ovisi funkcija bubrežnog presatka, kao i o ranoj poslijeoperacijskoj skrbi. Upravo zbog komorbiditeta koji prate ovu skupinu pacijenata, veoma je važna adekvatna prijeoperacijska priprema pacijenata čije opće stanje treba u najvišoj mogućoj mjeri optimalizirati do samog zahvata. Zadovoljavajućom volumskom optimalizacijom i održavanjem parametara hemodinamike unutar ciljanih vrijednosti, sprječavamo razvoj ishemijsko-reperfuzijske ozljede presatka. U daljnjem poslijeoperacijskom tijeku važno je na vrijeme prepoznati rane znakove mogućih komplikacija i prevenirati ih uz odgovarajuće mjere liječenja, kako bi se spriječilo neželjeno odbacivanje bubrežnog presatka.

Izjava o sukobu interesa: Autori izjavljuju da ne postoji sukob interesa.

\section{LITERATURA}

1. Baxi V, Jain A, Dasgupta D. Anaesthesia for Renal Transplantation: An Update. Indian J Anaesth 2009;53:13947.

2. Krishnan M. Preoperative care of patients with kidney disease. Am Fam Physician 2002;66:1471-6.

3. Tabriziani H, Baron P, Abudayyeh I, Lipkowitz M. Cardiac risk assessment for end-stage renal disease patients on the renal transplant waiting list. Clin Kidney J 2019;12: 576-85.

4. Joist H, Brennan DC, Coyne DW. Anemia in the kidneytransplant patient. Adv Chronic Kidney Dis 2006;13:410.

5. Boccardo P, Remuzzi G, Galbusera M. Platelet dysfunction in renal failure. Semin Thromb Hemost 2004;30: 579-89.

6. Perez-Saez MJ, Pascual J. Kidney Transplantation in the Diabetic Patient. J Clin Med 2015;4:1269-80.

7. Pavičić Šarić J, Jukić M, Videc Penavić L, Magdić Turković T, Bekavac I. Radna skupina HLK/HDAIL za prijeanestezijsku procjenu i pripremu odraslog pacijenta za operacijski zahvat ili dijagnostičko/terapijski postupak. Zagreb, 2017.

8. Kokot $F$, Wiecek A. Function of endocrine organs in kidney transplant patients. Ann Transplant 1996;1:23-8.

9. Pochineni V, Rondon-Berrios $\mathrm{H}$. Electrolyte and AcideBase Disorders in the Renal Transplant Recipient. Front Med (Lausanne) 2018;5:261.

10. Eng M, Brock G, Li X, Chen Y, Ravindra KV, Buell JF et al. Perioperative anticoagulation and antiplatelet therapy in renal transplant: is there an increase in bleeding complication? Clin Transplant 2011;25:292-6.

11. Bliven K, Snow K, Carlson A, Yeager S, Kenyon N, Smith L et al. Evaluating a Change in Surgical Antibiotic Prophylaxis in Kidney Transplant Recipients. Cureus 2018; 10(10):e3433. doi: 10.7759/cureus.3433.

12. Hultin S, Hawley C, Johnson DW, Francis RS. Perioperative Care for Kidney Transplant Recipients. In: Vitin A. Perioperative Care for Organ Transplant Recipient. IntechOpen, 2019. Available from: https://www.intechopen. com/books/perioperative-care-for-organ-transplant-recipient/perioperative-care-for-kidney-transplant-recipients

13. Robertson E, Logan N, Pace N. Anaesthesia for renal transplantation. Anesthesia \& Intensive Care Medicine 2018;19:552-6.

14. Schmid S, Jungwirth B. Anaesthesia for renal transplant surgery: an update. Eur J Anaesthesiol 2012;29:552-8.

15. O'Malley CM, Frumento RJ, Hardy MA, Benvenisty Al, Brentjens TE, Mercer JS et al. A randomized, doubleblind comparison of lactated Ringer's solution and 0,9\% $\mathrm{NaCl}$ during renal transplantation. Anesth Analg 2005; 100:1518-24.

16. Hadimioglu N, Saadawy I, Saglam T, Ertug Z, Dinckan A. The effect of different crystalloid solutions on acid-base balans and early kidney function after kidney transplantation. Anesth Analg 2008;107:264-9.

17. Horl WH. Nonsteroidal Anti-Inflammatory Drugs and the Kidney. Pharmaceuticals (Basel) 2010;3:2291-321.

18. Bacchi G, Buscaroli A, Fusari M, Neri L, Cappuccilli ML, Carretta $E$ et al. The influence of intraoperative central venous pressure on delayed graft function in renal transplantation: a single-center experience. Transplant Proc 2010;42:3387-91.

19. Ferris RL, Kittur DS, Wilasrusmee C, Shah G, Krause E, Ratner L. Early hemodynamic changes after renal transplantation: determinants of low central venous pressure in the recipients and correlation with acute renal dysfunction. Med Sci Monit 2003;9:CR61-6. 